\title{
Quality Assurance Program in Radiodiagnosis in a Tertiary Care Hospital in India
}

Pankaj Arora

\begin{abstract}
Context: The specialty of radiodiagnosis has been revolutionized by the advent of technology. This has put additional onus on the practitioners to maintain strict quality control to improve efficiency, lower exposure as well as cost.
\end{abstract}

Aims: The aim of the study is to determine quality assurance program in radiodiagnosis in order to identify the gaps and possible avenues of improvement.

Settings and design: The cross-sectional study was conducted in a tertiary care hospital in India in the second half of calendar year 2008.

Materials and methods: The department did not have a defined and documented quality assurance program. Hence, the factors which are part of such a QAP were identified and the practices in the department against those factors were compared. The scoring was done based on the degree of compliance; complete, partial or no compliance.

Results: A total of 23 parameters/subparameters were evaluated to find out the extent of quality assurance program being implemented in the study setting. Out of maximum 230, a score of 135 was achieved by the department.

Conclusion: The department of radiodiagnosis in the tertiary care institute need to institute a QAP for improving the quality and efficiency for better utilization of resources.

Keywords: Radiodiagnosis, Quality, Quality assurance program.

Key messages: Quality Assurance Program must be instituted in different departments, Radio diagnosis in the instant case, for efficient utilization, quality output and effective cost control. All these will contribute to patient safety practices.

How to cite this article: Arora P. Quality Assurance Program in Radiodiagnosis in a Tertiary Care Hospital in India. Int J Res Foundation Hosp Healthc Adm 2013;1(1):8-12.

Source of support: Nil

Conflict of interest: None

\section{INTRODUCTION}

Medical imaging has grown in leaps and bounds over the years and is looking to advance further. Newer imaging

\section{Assistant Professor}

Department of Hospital Administration, Postgraduate Institute of Medical Education and Research, Chandigarh, India

Corresponding Author: Pankaj Arora, Assistant Professor Department of Hospital Administration, Postgraduate Institute of Medical Education and Research, Chandigarh, India, e-mail: drpa1009@yahoo.co.in modalities and upgradation of the existing ones have made the diagnosis more precise and treatment more definitive. It is hard to imagine a time when radioimaging was not available even though Roentgen first radiographed his wife's hand only a little over a century back.

The improvement in the technology has come at a price. The equipment are very costly and the radiological investigations form a substantial part of the overall expenditure on treatment. ${ }^{1,2}$ The growth in advanced medical imaging is a major factor in the rising cost of medicare. ${ }^{3}$

It is ironical that unlike other industries, improvement in technology in health industry usually does not translate into decreased cost of service. The developed economies are struggling to meet the escalating cost of healthcare and the situation in developing countries is even grimmer. With scarce resources and growing demand, India faces the challenge of providing most modern expensive services to the patients as well as provisioning of basic health services for all the people. The two issues place conflicting demand on the limited resources devoted to this sector.

In case of radioimaging, it has to be kept in consideration that excess exposure to radiations does have detrimental effects on the patients. Therefore, it is very important the patients are not subject to unnecessary radiations. This can be achieved by rational approach to investigation as well as eliminating the need to re investigate because of poor quality.

The twin objectives of eliminating reinvestigation on account of poor quality and reducing the cost of radiodiagnosis can be achieved by instituting a quality assurance program in the discipline of radioimaging. Quality assurance as defined by ISO means part of quality management focussed on providing confidence that quality requirements will be fulfilled. It has been seen that a quality assurance program can result in tremendous reduction in cost due to elimination of wastage on images of nondiagnostic quality as well as decrease in unnecessary exposure. ${ }^{4}$ The American College of Radiology (ACR) estimates that quality standards can save approximately $\$ 5$ billion in medicare costs over 10 years. ${ }^{5}$ In fact according to health Canada these two, i.e. minimizing radiation exposure and cost effectiveness along with maintenance of the quality of diagnostic images are the three secondary objectives of a quality assurance program in Radiology. The primary objective is to ensure the consistent provision of prompt and accurate diagnosis of patients. ${ }^{6}$ 


\section{MATERIALS AND METHODS}

A cross-sectional study was conducted to evaluate the measures being taken to assure quality in the Radiology Department in a public sector tertiary care hospital located in a metropolis in India. The hospital has different wings with each wing having its own radiological installations except MRI which is a common facility. The radiology department located in the largest wing with more than 1,000 beds was studied during the second half of year 2008. In the year 2008 to 2009 , the department conducted more than one hundred thousand X-ray investigations in the outpatient setting and another ninety thousand in Emergency and Inpatient Department. During this period more than Fifty thousand ultrasonograms and more than fifteen thousand CT scans were carried out. Besides these the department also performed special investigations like IVP, Barium studies and assisted in guided tests like biopsy, etc.

Despite the workload, the department did not have a documented quality assurance program (QAP). Hence, a checklist was formulated to assess different aspects of a QAP. The parameters were divided into structure, process and outcome measures and were derived from the literature and discussions with peers and experts. The parameters were further subdivided wherever required. The adherence to the parameters was evaluated as fully compliant, partial compliant or noncompliant and scored accordingly as 10 , 5 or 0 respectively. The scoring pattern is similar to the one adopted by National Accreditation Board for Hospitals and Healthcare Providers for scoring during the accreditation of the healthcare organizations.

\section{OBSERVATIONS}

A total of 23 parameters/subparameters were evaluated to find out the extent of QAP being implemented in the study setting. Since there was no documented QAP, the elements were enumerated and evaluated assuming that these would have been part of any such program.

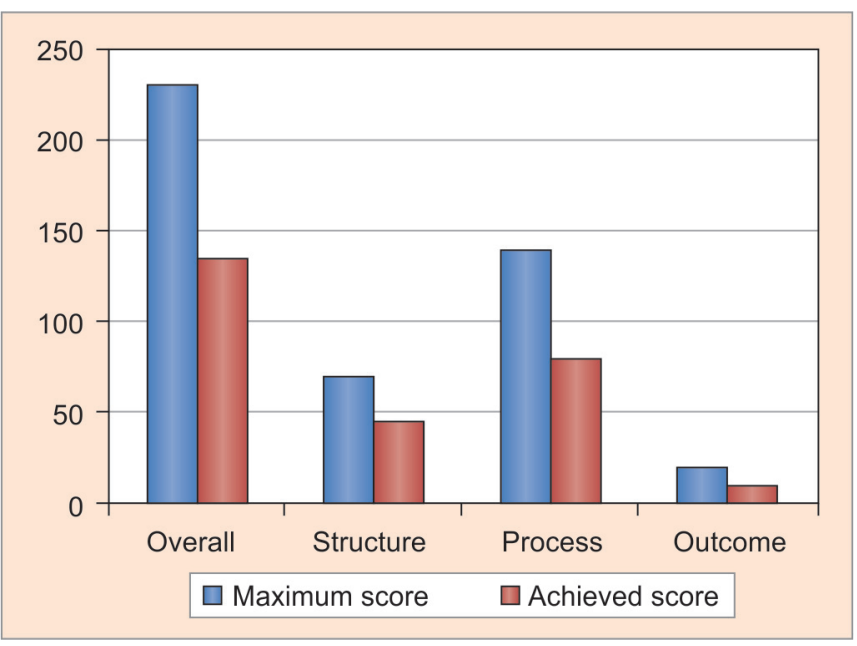

Fig. 1: Scores achieved by the department

The maximum possible score based on full compliance (i.e. score of 10) of each parameter/subparameter was 230. The structural elements could have a maximum score of 70 while process elements could have a maximum score of 140 . The table below shows the maximum score and the score achieved by the Department of Radiology.

The detailed scores under each heading, i.e. structure, process and outcome are depicted in Tables 1 to 3 .

\section{DISCUSSION}

Quality assurance in radiology is a management tool which aims to ensure that every procedure is necessary and appropriate and is done safely to the satisfaction of patients and referring physician. ${ }^{7}$

Quality assurance program for radiology should have the following elements: ${ }^{8}$

a. Authority and responsibility for the implementation of QAP should be delineated.

b. Quality control monitoring and maintenance program should be established.

c. Frequent evaluation of the quality control tests and effectiveness of the program should be done.

d. Standards for image quality based on subjective or objective criterion should be established.

Table 1: Compliance to structure parameters

\begin{tabular}{|c|c|c|c|c|}
\hline S.no & Parameter & $\begin{array}{l}\text { No } \\
\text { compliance } \\
\text { (0) }\end{array}$ & $\begin{array}{l}\text { Partial } \\
\text { compliance } \\
\text { (5) }\end{array}$ & $\begin{array}{l}\text { Full } \\
\text { compliance } \\
\text { (10) }\end{array}$ \\
\hline 1. & Physical structure (Conformance to AERB guidelines) & & & $\sqrt{ }$ \\
\hline 2. & Signages (Radiation Hazard, PCPNDT Act, Procedure is on, Metallic prosthesis, etc.) & & $\sqrt{ }$ & \\
\hline 3. & Waiting area (Adequacy, Disabled friendly) & & $\sqrt{ }$ & \\
\hline 4. & Privacy (Changing room, Authorized entry) & & $\sqrt{ }$ & \\
\hline 5. & Equipment (Acceptance tests, QC tests) & & & $\sqrt{ }$ \\
\hline 6. & PPE (Lead aprons, Gonadal \& thyroid shields, Glasses to workers \& patients) & & $\sqrt{ }$ & \\
\hline 7. & Resuscitation equipment, especially in areas of interventional radiology & & $\sqrt{ }$ & \\
\hline
\end{tabular}




\begin{tabular}{|c|c|c|c|c|}
\hline S.no & Parameter & $\begin{array}{l}\text { No compliance } \\
\text { (0) }\end{array}$ & $\begin{array}{l}\text { Partial compliance } \\
\text { (5) }\end{array}$ & $\begin{array}{l}\text { Full compliance } \\
\text { (10) }\end{array}$ \\
\hline \multirow[t]{5}{*}{1.} & Patient safety: & & & \\
\hline & (a) Patient identification & & $\sqrt{ }$ & \\
\hline & (b) Informed consent & & $\sqrt{ }$ & \\
\hline & (c) History & & & $\sqrt{ }$ \\
\hline & (d) Universal precautions & & $\sqrt{ }$ & \\
\hline \multirow[t]{4}{*}{2.} & Radiation exposure: & & & \\
\hline & (a) Radiographic positioning manual & $\sqrt{ }$ & & \\
\hline & (b) Loading factors manual & $\sqrt{ }$ & & \\
\hline & (c) ESE & $\sqrt{ }$ & & \\
\hline \multirow[t]{4}{*}{3.} & Health worker safety: & & & \\
\hline & (a) Radiation dose monitoring & & & $\sqrt{ }$ \\
\hline & (b) Needle stick injury & & & $\sqrt{ }$ \\
\hline & (c) Pregnant employee & & & $\sqrt{ }$ \\
\hline 4. & Training & & $\sqrt{ }$ & \\
\hline 5. & $\begin{array}{l}\text { Reporting incl. urgent reporting, clinical } \\
\text { correlation, reduction in reporting time. }\end{array}$ & & & $\sqrt{ }$ \\
\hline \multirow[t]{3}{*}{6.} & Miscellaneous: & & & \\
\hline & (a) Biomedical waste disposal & $\sqrt{ }$ & & \\
\hline & (b) Safe storage of narcotic drugs & & & $\sqrt{ }$ \\
\hline
\end{tabular}

e. Training and retraining of the personnel to upgrade the skills should be undertaken.

f. Records should be maintained and a written quality assurance manual should be made available to all the personnel.

Although different countries may have instituted QAP in their setup, e.g. JCAHO standards are being followed in US but it is essential that the standards are modified according to the region so as to develop a country specific or institution specific QAP. ${ }^{9}$ But, the position statement of ACR enunciates certain elements which have universal application in any setting. These are equipment quality control, infection control, patient and health worker safety and patient education. ${ }^{10}$ These and other elements were included in the checklist which was devised to measure the compliance to a QAP.

\section{STRUCTURE}

Under the broad heading of structure: (a) physical structure of the room, (b) waiting area, (c) privacy, (d) signage, (e) equipment, (f) personnel protective equipment, (g) resuscitation equipment were studied. Any radiological installation in India has to follow the AERB guidelines as minimum essential criterion for structural safety before it is allowed to function. The department studied was no exception to this. Scientifically designed signage facilitates the movement of patients and warns patients in case of potential hazards. The signage should be placed to warn the visitors regarding the hazards of radiation, any statutory obligation (e.g. PCPNDT Act-1994) and to inform when the procedure is undertaken in at least two languages. While statutory requirements were being followed, deficiencies were noted on other aspects. Due to the constraints of the space, the waiting area was insufficient to meet the needs of the patients. The privacy being provided to the patient while preparation (e.g. change of dress) as well as during the procedure (e.g. prevention of entry of nonauthorized personnel) is important to respect the dignity of the patient as well as instilling confidence in the patient regarding the services being offered. The department was partially compliant, with the provision of changing rooms only for the female patients and needs to do more to prevent intrusions by other visitors during the procedure.

Equipment being used are key elements for the successful functioning of any radiology department and most of the attention regarding quality control is generally focussed on this. Appropriate specifications, proper procurement procedure, quality control (QC) tests before installation and before and after commissioning, and regular maintenance (preventive as well as breakdown) are essential to achieve

Table 3: Compliance to outcome parameters

\begin{tabular}{lllll}
\hline S.no & Parameter & No compliance & $\begin{array}{l}\text { Partial compliance } \\
(5)\end{array}$ & $\begin{array}{l}\text { Full compliance } \\
(10)\end{array}$ \\
\hline 1. & RRAP & $(0)$ & & $\sqrt{ }$ \\
2. & Duplicate reports & $\sqrt{ }$ & $\sqrt{ }$ \\
\hline
\end{tabular}


maximum utilization and efficiency. As mentioned earlier, a department has to make its own guidelines based on its requirements, availability of trained manpower as well after sales support to derive policy regarding equipment. The department was fulfilling all the components in this regard. Additionally, AERB is recommending all the vendors to perform quality assurance tests which further strengthen the quality control measures.

Personnel protective equipment (PPE) including lead aprons, gonad and thyroid shields are essential to prevent un-necessary radiation exposure to the staff as well as visitors. Even though PPE were being provided to the users; their upkeep was improper leading to probable breach in the protection being offered by these. The nursing orderlies were seen folding lead aprons while carrying these even though stands were provided.

The radiological procedures carried out are generally safe other than the effects of the radiation. But the patients may themselves be suffering from conditions which can lead to sudden complications. The use of low-osmolar nonionic contrast agents is associated with fewer adverse reactions than the high-osmolar agents. ${ }^{11,12}$ Yet the requirement for lifesaving measures cannot be ruled out completely. Certain intervention procedures also carried out, e.g. ultrasound guided biopsy or aspiration. These may also result in unexpected reactions. The department was storing lifesaving medications in few areas only.

\section{PROCESS}

Quality and patient safety are the two pillars of any accreditation process. The magnitude of the damage caused due to harm rendered to patients has been amply brought out by the famous IOM report: To err is human. Thus, patient safety was taken as one of the important cornerstone of QAP. Under the ambit of patient safety four key parameters were analyzed. These are: (a) patient identification, (b) informed consent, (c) history, and (d) universal precautions. During the observation of the practices being followed it was found that patients were identified by one method, i.e. radiologist calling out the name of the patient, which was less than desirable. At least two methods should be used since it is highly likely that more than two patients would have similar names or similar sounding names. The patients were not completely informed before consent was being taken and more time needs to be devoted to explain the aspects of intervention being planned. The history was being taken properly and the radiologist was not merely relying on the history being provided by the referring physician. Universal precautions were not being followed rigorously.

\section{ALARA Principle}

Provision of best possible diagnostic information at a minimal radiation dose, i.e. ALARA principle (As Low As Reasonably Achievable) is a basic aim of QAP in radiology. ${ }^{13}$ The three factors related to radiation exposure of the patients; radiographic positioning, loading factors and entrance skin exposure (ESE) were studied. The department had not placed any manual for these three at the place of exposure and hence were labelled as noncompliant on these counts.

\section{Employee Safety}

Along with the safety of the patients, health worker safety also needs to be ensured. The radiation dose monitoring was being done with TLD batches and there were established protocols for needle stick injury as well as regarding pregnant employees.

\section{Training}

All the employees including radiographers were qualified and trained in their respective field but the department was lacking in efforts to provide continuous training in the form of CME or workshop to its radiographers.

\section{Reporting}

The results of different investigations were conveyed in time as per the policy of the hospital and in cases of abnormal results or findings requiring immediate attention of the physician; they were being conveyed on the phone. Cases were also being discussed in common clinical correlation meetings for the benefit of patients as well as referring physicians and radiologists.

\section{Miscellaneous}

While the narcotic drugs were safely stored, biomedical waste was not being disposed off properly. Since it is a statutory requirement, hence, to emphasize its importance, it was assessed as noncompliant.

\section{OUTCOME}

Duplicate reports were being issued on demand but the department had not instituted any program akin to reject or repeat analysis program. The analysis of the radiographs being rejected as insufficient by the referring physician as well as by radiologist and the requests to repeat the X-rays for any reason must be analyzed to determine the cause. This can point out the problem with the machine or men. Suitable measures could be taken based on the results of the analysis. This will prevent the recurrence of errors in future. 
The department should set the acceptable benchmarks and try to improve upon. However, with the increased use digital $\mathrm{X}$-ray equipments where image quality can be modified, the importance of such a program may decrease.

\section{CONCLUSION}

Quality in medical imaging is aptly defined as 'a timely access to and delivery of integrated and appropriate radiological studies and interventions in safe and responsive facility and prompt delivery of accurately interpreted reports by capable personnel in an efficient, effective and sustainable manner'. The different components of the definition cover the aspects which should be catered for when devising a QAP for Radiology Department. The commitment of the top leadership at the level of the department as well as hospital is essential for survival of such a program. The formation of quality assurance manual is absolutely necessary to operationalize such a program. And such a documented QAP is required to provide effective, efficient, timely and safe services to the patients as well as community.

\section{REFERENCES}

1. Turkcuer I, Serinken M, Karcioglu O, Zencir M, Keysan MK. Hospital cost analysis of management of patients with renal colic in the emergency department. Urological Research 2010;38(1):29-33
2. Hillman BJ. New imaging technology and cost containment. AJR 1994;162:503-506.

3. Available at: http://www.qualityimaging.org/. Accessed on 7th June, 2011.

4. Quality assurance in Diagnostic radiology: A guide prepared following a workshop held in Neuherberg, Germany, October 1980; Geneva: WHO;1982. p. 20-24.

5. Available from: http://www.qualityimaging.org/costsavings/ index.asp. Accessed on 7th June, 2011.

6. Available at: http://www.hc-sc.gc.ca/ewh-semt/pubs/radiation/ quality-assurance_art-qualite/.Accessed on 8th June, 2011.

7. Organization, development, quality assurance and radiation protection in radiology services: imaging and radiation therapy. Pan American Health Organization. Washington, D.C.:PAHO; 1997.

8. Available from: http://www.health.state.mn.us/divs/eh/radiation/ xray/archives/qa.pdf. Accessed on 8th June, 2011.

9. Jimenez P, Borras C, Fleitas L. Accreditation of diagnostic imaging services in developing countries. Rev Panam Salud Publica 2006;20(2/3):104-112.

10. Available at: http://www.acr.org/SecondaryMainMenu Categories/quality_safety/guidelines/position_statement.aspx. Accessed on 8thJune, 2011.

11. Maddox TG. Adverse reactions to contrast material:recognition, prevention, and treatment. Am Fam Physician 2002;66: $1229-1234$.

12. ACR practice guideline for the use of intravascular contrast media. Accessed from:http://www.acr.org/ SecondaryMainMenuCategories/quality_safety/RadSafety/ OtherSafetyTopics/intravascular-contrast.aspx.Accessed on 10th June, 2011.

13. Mihic MS, Mestrovic T, Prlic I, Suric D. Importance of Quality Assurance Program Implementation in Conventional Diagnostic Radiology. Coll Antropol 2008;32(Suppl 2):181-184. 